\title{
Comunicação breve \\ Desafios da sistematização do direito sanitário: da consolidação normativa ao desenvolvimento teórico e dogmático
}

Brief communication

Challenges of the systematization of health law: from normative consolidation to theoretical and dogmatic development

Comunicación breve

Desafíos de la sistematización del derecho sanitario: desde la consolidación normativa hasta el desarrollo teórico y dogmático

Jairo Bisol ${ }^{1}$

\section{Resumo}

A inflação de atos normativos nos estados contemporâneos é fenômeno que compromete a unidade e sistemacidade do direito à saúde, com reflexos diretos no alcance dos princípios e conceitos estruturantes das políticas públicas de saúde, e no próprio enfraquecimento da legislação do Sistema Único de Saúde. O recurso que se aponta para enfrentamento dessa questão é a consolidação dos atos normativos como estratégia de defesa e garantia de efetivação do direito à saúde.

Palavras-chave: Direito à saúde. Normas jurídicas. Judicialização da saúde

\begin{abstract}
Inflation of acts in contemporary states compromises the right to health in their unity and systematization, with direct consequences for the principles and structuring concepts of health public policies, and the weakening of the Brazilian Unified Health System (SUS) legislation. One resource that addresses this issue is the consolidation of acts as a defense strategy and guaranteeing the right to health.
\end{abstract}

Keywords: Right to health. Enacted statutes. Health's judicialization

\section{Resumen}

La inflación de los actos normativos en los estados contemporáneos es un fenómeno que compromete la unidad y sistematización del derecho a la salud, con consecuencias directas en el alcance de los principios y conceptos estructurantes de las políticas de salud pública, y el debilitamiento de la legislación del Sistema Único de Salud. La salida que enfrenta este problema es la consolidación de los actos normativos como estrategia de defensa y garantía del derecho a la salud.

Palabras Ilave: Derecho a la salud. Normas jurídicas. Judicialización de la salud

\footnotetext{
1 Doutor em Direito pela Universidade Federal de Pernambuco; membro auxiliar da Comissão de Aperfeiçoamento e Fomento da Atuação do Ministério Público na Saúde, do Conselho Nacional do Ministério Público, Brasília, DF, Brasil. Email: jairo@mpdft.gov.br
} 
A história registra mudanças radicais nas estratégias e nas práticas administrativas, legislativas e jurisdicionais, rearranjos decorrentes das transformações político-econômicas do Estado de Direito. Com o advento do Estado Social, o ímpeto moderno de reduzir o ordenamento jurídico a um pequeno número de estatutos legais codificados que regulassem cada campo temático sistêmica e exaustivamente deu lugar a um processo de legislação através de pequenas leis esparsas que resultou na descodificação do direito. De igual modo, a expansão desenfreada da elaboração do direito por atos normativos resultantes do exercício de competência administrativa deu início à deslegalização do direito. Descodificado e deslegalizado, o direito passou a conviver com a proliferação inflacionária de suas pautas normativas, fenômeno que comprometeu sua unidade e sua sistematicidade. Em linhas gerais, esse quadro se estende até os dias de hoje.

A função sistematizadora do direito, antes exercida pelas partes gerais dos códigos e suas respectivas construções teoréticas, deslocou-se para a força harmonizadora e generalizante dos princípios jurídicos consagrados na constituição, dando início ao fenômeno da constitucionalização dos direitos e à luta pela jurisdição constitucional. Os direitos fundamentais, positivados do texto constitucional, nasceram e vicejaram na dependência da força normativa da constituição: para garantir a sua efetividade foi preciso emprestar aplicabilidade aos preceitos constitucionais.

Do ponto de vista de sua pretensão sistematizadora, a tentativa de usar da função harmonizadora dos princípios constitucionais para garantir a unidade do direito vem apresentando resultados insuficientes. Não é difícil perceber que a multiplicação inflacionária das pautas normativas infraconstitucionais compromete significativamente a coerência interna da ordem jurídica vigente, reduzindo a pó o modelo subsuntivo de jurisdição e suas crenças no controle racional do direito e previsibilidade das decisões judiciais. Essa perda de sistematicidade fulmina o alcance de princípios e de conceitos estruturantes do sistema de direito legislado, tais como os de vinculação, imparcialidade e segurança jurídica, impondo aos juízes de direito - especialmente no campo da judicialização das políticas públicas - os imensos desafios de um crescente e inafastável protagonismo judicial, tarefa para a qual a magistratura não foi institucionalmente concebida.

O direito estatal se transforma num extenso, complexo e desordenado cipoal de estatutos normativos de pequeno porte (leis esparsas e atos normativos), muitos forjados 
em linguagem tecnicista, perseguindo resultados casuísticos, sem maiores compromissos com o princípio da unidade legal. Não raro regulamentam um mesmo assunto em comandos esparsos, assistemáticos e, por vezes antinômicos, seguidos pelo uso abusivo da fórmula genérica e indeterminada da revogação das disposições em contrário e pela progressiva marginalização das técnicas legislativas originárias da codificação sistematizadora, técnicas essas voltadas à necessidade de se imprimir coerência lógica aos corpos normativos mais extensos e complexos - tais como os que regulamentam as políticas públicas - de modo a facilitar a atividade jurisdicional e, ao mesmo tempo, impor limites objetivos ao seu exercício. Não há como vincular o magistrado a um direito que perdeu a sua unidade e sistematicidade: o sistema determina o que é problema, oferecendo uma única resposta normativa. Um direito assistemático assume a condição catalográfica ao oferecer várias opções normativas ao aplicador, inviabilizando a sua vinculação. Trocando em miúdos, não se vincula o juiz a um catálogo normativo; vincula-se o juiz a um sistema normativo! Não por outro motivo a lei é a única fonte vinculante. Outras fontes clássicas como a doutrina e a jurisprudência, estruturadas de forma catalográfica, não possuem o condão de vincular o magistrado, apenas persuadir. Ora, empurrada pela obrigação de decidir imposta pelo princípio do non liquet, diante de um direito que perdeu a sua sistematicidade não resta outra opção à magistratura senão exercer o ativismo judicial.

É preciso compreender com clareza essa cena onde se construiu - e ainda se constrói - o arcabouço normativo infralegal da política pública de saúde, hoje traduzido num imenso emaranhado de portarias fragmentárias e difusas, onde o "mínimo sistemático" sucumbe diante da irracionalidade resultante da profusão de atos normativos, provocando uma significativa e preocupante indeterminação do direito e expondo ainda mais a saúde pública a uma judicialização - já por tantos outros motivos - perigosamente desenfreada. Por esse viés, ao volume tsunâmico da judicialização da saúde se acrescenta a força desestruturante do ativismo judicial, tornando a cena explosiva do ponto de vista da necessidade de racionalidade da gestão, especialmente em tempos de crise.

Nesse contexto bastante irracional, a legislação ordinária do SUS resta cada vez mais enfraquecida e achatada entre o poder regulamentar casuístico da administração e a indeterminação dos limites normativos dos princípios gerais constitucionalizados. De um lado, o casuístico exercício do poder e sua profusa elaboração normativa inflacionando o já 
extenso mercado das regras jurídicas; de outro, princípios constitucionais que firmam de um modo excessivamente abstrato - e, por isso mesmo, vagos e indeterminados - valores, metas e objetivos a serem cumpridos pela ordem jurídica positiva.

Esse quadro típico do Estado contemporâneo - em grande medida resultante do deslocamento da atividade de elaboração do direito do poder legislativo para executivo visando garantir o poder regulamentar das políticas públicas à gestão administrativa imprimiu ao direito sanitário um significativo nível de indeterminação normativa e, como desdobramento inevitável, um intenso ativismo judicial na sua tutela jurisdicional: o exercício da competência e da função regulamentar da política pública sofre um deslocamento, via jurisdição, da gestão administrativa para a magistratura. O ganho de irracionalidade se multiplica em face da natureza essencialmente casuística da decisão judicial.

Outro efeito perverso desse fenômeno é o enfraquecimento do Sistema Único de Saúde (SUS) na balança política das composições de governo, especialmente nos embates com a área econômica. Sem sombra de dúvidas, é mais fácil acomodar os conflitos internos das estruturas de governo seguindo a cartilha dos setores empoderados da área econômica quando as políticas sociais são regidas por um direito sem força sistemática, uma ordem jurídico-normativa flexível, manipulável e de frágil poder de vinculação e proteção judiciária.

Diante desse quadro, proteger a política pública de saúde da judicialização desenfreada e seu impacto desestruturante sobre a gestão do SUS passa pelo desenvolvimento urgente de estratégias de sistematização do direito sanitário. Uma estratégia primeira e inadiável, sem dúvida, consiste em mudanças na forma do gestor exercer o poder regulamentar: é preciso que a gestão federal do SUS perceba, imediatamente, a importância da consolidação do emaranhado de atos normativos do Ministério da Saúde. Se impõe à gestão do SUS o exercício do poder regulamentar de forma menos casuística e mais comprometida com a coerência normativa do sistema: o que ao fim e ao cabo, significa exercer o poder regulamentar para garantir uma efetividade mais consistente e consolidante da política pública, o que por vezes desautoriza opções efêmeras e setoriais impostas por interesses imediatistas do poder político. O exercício do poder regulamentar deve assumir a necessidade da consolidação e sistematização do direito sanitário infralegal, o que pressupõe uma boa dose de blindagem da gestão da saúde de fatores mais irracionais - e, por vezes, eleitoreiros - do exercício do poder estatal nas 
modernas democracias. O descaso e a incompreensão da dinâmica do poder regulamentar é um dos principais fatores de escancaro da porta da judicialização desenfreada e do ativismo da magistratura, eis que transfere inadvertidamente este poder administrativo para a casuística desestruturante da decisão judicial. Um grave erro de estratégia na gestão do SUS.

O que se percebe é que essas mudanças estruturais do direito, embora em processo de avanço e consolidação há mais de meio século, ainda demandam profundas alterações nas práticas administrativas e judiciárias. Os operadores da tsunâmica onda de judicialização que se abate sobre a política pública de saúde, por sua vez, insistem em adotar estratégias processuais inspiradas nos velhos paradigmas jurídicos da modernidade. Ora, não me parece difícil intuir que a proteção judiciária dos direitos sociais - e das políticas que os garantem - não encontrará respostas estruturantes nos clássicos modelos da tutela coativo-repressiva, do direito penal, ou restitutivo-indenizatório, do direito civil. É sintomática a dificuldade do jurista com este tipo de formação obsoleta equacionar adequadamente e operar com eficiência as questões relativas à proteção da saúde pública e à aplicação das normas do direito sanitário. Urge desjudicializar ao limite a política pública de saúde.

Ante a crise radical do sistema jurídico da modernidade resta aos direitos sociais dependentes de políticas públicas a tomada de consciência da necessidade premente de lutar pela consolidação de seus corpus normativos como estratégia de defesa de ondas judicializantes e de garantia de sua efetivação. De igual modo, impõe-se aos juristas, também responsáveis pela efetivação dos direitos, a tarefa hercúlea do desenvolvimento de uma metódica jurídica capaz de instrumentalizar o pensamento jurídico-decisório para o enfrentamento desses novos desafios de forma atenta e comprometida com critérios equilibrados de divisão das funções no exercício do poder estatal.

Aos olhos do gestor, um avanço significativo nas suas práticas administrativas. Em especial, no domínio estratégico do exercício do poder de regulamentação das políticas públicas, de modo a protegê-lo do impacto desestruturante da judicialização.

Aos olhos do jurista, um caldo de cultura de extrema fertilidade para uma nova dogmática jurídica, atualizadora das práticas jurídicas e comprometida com a efetivação dos direitos de última geração, movida por um pensamento capaz de exorcizar os fantasmas do passado, os ícones sagrados de uma modernidade já perdida no tempo, mas cujo espectro 
irresistível insiste em assombrar consciência dos juristas contemporâneos. Enfim, um pensamento que não se renda à redução analítica pretendida pelo cientificismo moderno, que durante muito tempo ocultou, de um lado, a natureza prudencial do direito e, de outro, a necessidade cada vez premente de se imprimir à dimensão jurídica do fenômeno social uma vocação e um destino ético-políticos que pairem acima das ideologias de plantão.

Como citar esse artigo:

Bisol J. Desafios da sistematização do direito sanitário: da consolidação normativa ao desenvolvimento teórico e dogmático. Cadernos Ibero-Americanos de Direito Sanitário. 2019 jul./set.; 8(3): 173-177.

http://dx.doi.org/10.17566/ciads.v8i3.580 